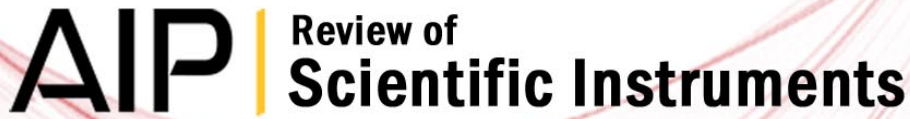

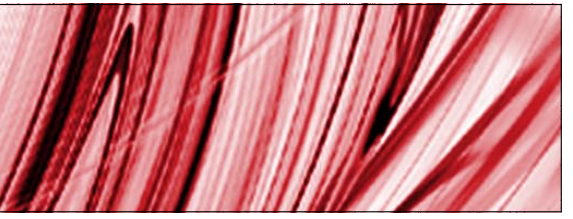

An RF-powered micro-reactor for the detection of astrobiological target molecules on planetary bodies

Valerie J. Scott, Margaret Tse, Michael J. Shearn, Peter H. Siegel, and Xenia Amashukeli

Citation: Rev. Sci. Instrum. 83, 084102 (2012); doi: 10.1063/1.4746994

View online: http://dx.doi.org/10.1063/1.4746994

View Table of Contents: http://rsi.aip.org/resource/1/RSINAK/v83/i8

Published by the American Institute of Physics.

\section{Related Articles}

Sagdeev potential analysis for positively charged dust grains in nonthermal dusty plasma near Mars Phys. Plasmas 14, 103703 (2007)

Two-component heterogeneous nucleation kinetics and an application to Mars

J. Chem. Phys. 127, 134710 (2007)

The biology instrument for the Viking Mars mission

Rev. Sci. Instrum. 49, 139 (1978)

\section{Additional information on Rev. Sci. Instrum.}

Journal Homepage: http://rsi.aip.org

Journal Information: http://rsi.aip.org/about/about_the_journal

Top downloads: http://rsi.aip.org/features/most_downloaded

Information for Authors: http://rsi.aip.org/authors

\section{ADVERTISEMENT}

\section{ORTEC MAESTRO ${ }^{\circ}$ V MCA Software}

For over two decades, MAESTRO has set the standard for Windows-based MCA Emulation. MAESTRO Version 7.0 advances further:

New! Windows 7 64-Bit Compatibility with Connections Version 8

New! List Mode Data Acquisition for Time Correlated Spectrum Events

New! Improved Peak fit calculations

New! Improved graphics handling for multiple displays

New! Open spectrum files directly from Windows Explorer

New! Improved performance with Job Functions and display updates

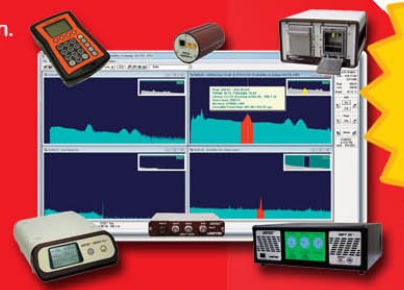




\title{
An RF-powered micro-reactor for the detection of astrobiological target molecules on planetary bodies
}

\author{
Valerie J. Scott, Margaret Tse, Michael J. Shearn, Peter H. Siegel, and Xenia Amashukelia) \\ Jet Propulsion Laboratory, California Institute of Technology, Pasadena, California 91109, USA
}

(Received 15 April 2012; accepted 4 August 2012; published online 30 August 2012)

\begin{abstract}
We describe a sample-processing micro-reactor that utilizes $60 \mathrm{GHz}$ RF radiation with approximately $730 \mathrm{~mW}$ of output power. The instrument design and performance characterization are described and then illustrated with modeling and experimental studies. The micro-reactor's efficiency on affecting hydrolysis of chemical bonds similar to those within large complex molecules was demonstrated: a disaccharide-sucrose-was hydrolyzed completely under micro-reactor conditions. The products of the micro-reactor-facilitated hydrolysis were analyzed using mass spectroscopy and proton nuclear magnetic resonance analytical techniques. () 2012 American Institute of Physics. [http://dx.doi.org/10.1063/1.4746994]
\end{abstract}

\section{INTRODUCTION}

Whether life exists elsewhere in the Universe other than our planet Earth remains one of the paradigm-shifting and fascinating questions for the scientific community and general public alike. The search for extant and/or extinct life in space has always been one of the major goals of the U.S. Space Exploration Missions to Mars and other planetary bodies. ${ }^{1}$ Various approaches and corresponding technologies have been proposed to enable the search for life, including the direct approach of processing planetary regolith and ices for the detection of life's chemical signatures-biomarkers. The detection and characterization of these chemical biomarkers would enable a better understanding of sustainability and evolution of life on inner- and outer-planetary bodies, asteroids, and comets.

There is large number of planetary bodies in our Solar System that may currently harbor life or may have in the past. Mars has been the primary focus of planetary exploration for many years. There is evidence that liquid water, one of the prerequisites for life as we understand it, once persisted on the surface ${ }^{2-6}$ and may still be present. ${ }^{7}$ Another interesting exploration target is the icy Jovian moon, Europa. It contains a liquid water ocean under its thick icy shell and many of the elements believed to be necessary for life. ${ }^{8,9}$ Saturn's moon, Titan, is known to have lakes containing not water, but liquid methane and an atmosphere similar to that which may have existed on early Earth. ${ }^{10-12}$ Near-Earth objects, such as asteroids, may contain chemical information about the very beginnings of the Solar System. ${ }^{13}$ These are just a few among many interesting targets for possible space exploration missions.

The successful detection of chemical biomarker molecules (such as organics that may be locked inside planetary regolith) will rely heavily on many experimental factors, including the availability of robust sample-processing instrumentation and high-sensitivity detectors and analyzers. The results of Mars Viking Mission gas chromatography-

a) Author to whom correspondence should be addressed. Electronic mail: Xenia.Amashukeli@jpl.nasa.gov. Present address: Caltech, 1200 E. California Blvd., MC 132-80, Pasadena, California 91125, USA. mass spectroscopy (GCMS) experiments ${ }^{14-19}$ provide a good lesson for the future missions on how the combination of high-sensitivity detectors, efficient extraction instrumentation, and the robotic capability to obtain subsurface samples may be needed in order to provide conclusive evidence for the presence or absence of biomarkers on Mars and other planetary bodies.

Our research focuses on the development of sampleprocessing instrumentation that will enable efficient extraction of biomarkers from the planetary regolith and ices by facilitating the breaking of bonds between target molecules and regolith and hydrolysis of complex polymeric materials into simpler units that are easier to detect and characterize. A radio frequency (RF)-powered micro-reactor was designed for these purposes. This instrument utilizes water-a single, readily available, high-purity, and non-toxic solvent, which is subjected to $730 \mathrm{~mW} 60 \mathrm{GHz} \mathrm{RF}$ radiation. This technology offers a simplified alternative approach to the "gold-standard" extractions, which typically require very specific experimental conditions for different classes of target biomarker molecules.

The micro-reactor leverages the operational principles of the subcritical water extractor (SCWE) instrument, ${ }^{20,21}$ which has been shown to successfully extract amino acids from terrestrial Mars-analog samples collected in the arid Yungay region of the Chilean Atacama Desert. Both instruments use high-temperature and high-pressure water to enable extractions and hydrolysis. Unlike SCWE, the micro-reactor requires lower power to operate and is more compact; therefore, it could be accommodated more easily within different scientific payload configurations. In addition, this new instrument would be useful in a variety of terrestrial applications that require extraction and hydrolysis of various compounds, such as searching for industrial pollutants found in soils and water.

In order to efficiently extract biomarkers, some of their chemical bonds may have to be hydrolyzed with minimal decomposition, yielding smaller fragments that are easier to detect and characterize. The RF-powered micro-reactor technology allows for substantial control over the experimental process that ultimately enables efficient extraction 

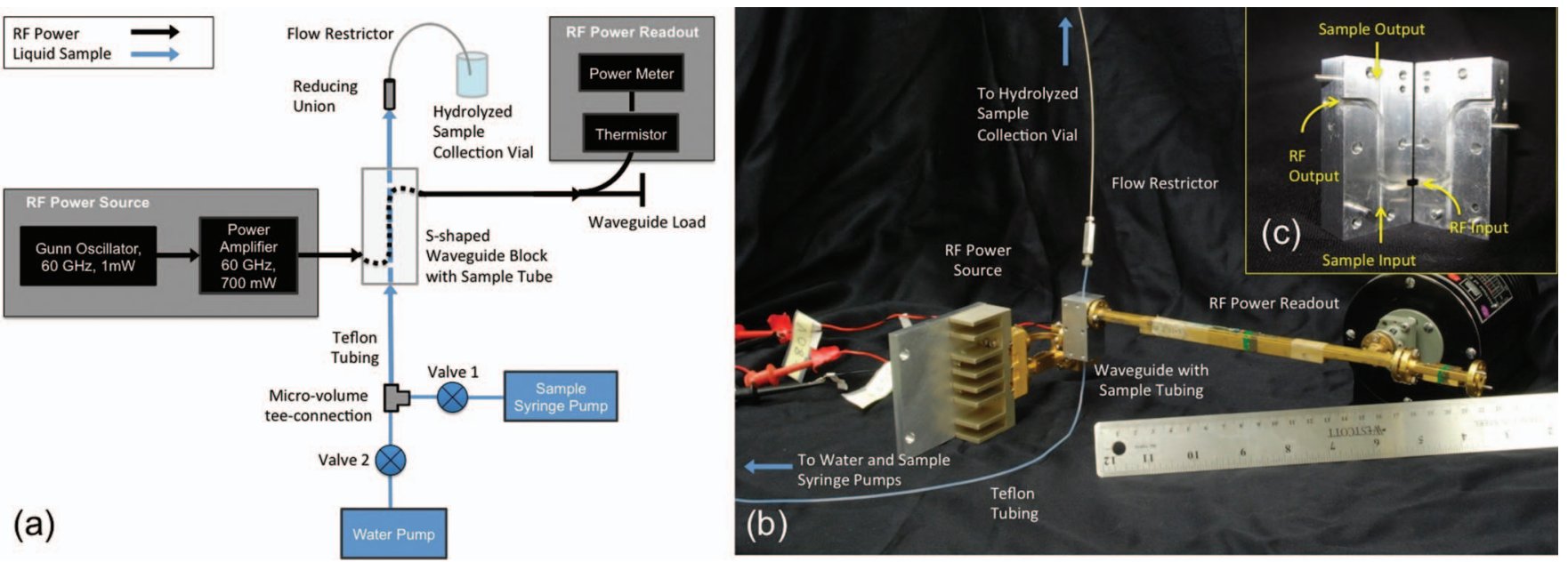

FIG. 1. (a) Diagram of the micro-reactor major components. (b) Photograph of the RF-powered micro-extractor and (c) the S-shaped waveguide.

and hydrolysis of target compounds with minimal loss of important chemical information.

The hydrolysis of the disaccharide sucrose in the presence of dilute acid was used to demonstrate the microreactor's operation. Sucrose's glycosidic bond bridging two monosaccharides is not hydrolyzed at a significant rate by simple exposure to water at ambient temperature and pressure $\left(\mathrm{t}_{1 / 2} \sim 440\right.$ years $){ }^{22}$ This reaction barrier can be lowered in acidic solution at higher temperatures. ${ }^{23}$ The rapid ( $<1$ min) hydrolysis of sucrose in the RF-powered microreactor provides insight into the utility of this technology and its potential applications. A later publication will discuss the broader functionality of the RF-powered micro-reactor technology.

\section{EXPERIMENTAL}

Figure 1 shows a schematic diagram (Figure 1(a)) and photographs of the RF micro-reactor assembly (Figure 1(b)) and the S-shaped waveguide block (Figure 1(c)). The microreactor consists of two distinct assemblies: the $60 \mathrm{GHz} \mathrm{RF}$ power chain incorporates the power source and waveguide block, and the sample-handling system includes components such as a water pump, sample tubing, and a sample-collection vial (Figure 1(a)).

The RF-power source consists of a custom-built fixed frequency $(60 \mathrm{GHz})$ millimeter wave generator (Quinstar Inc.) and a coupling waveguide that focuses the power onto the flowing aqueous sample (Figure 1(b)). The millimeter wave source contains a free-running $60 \mathrm{GHz}$ Gunn diode oscillator coupled to a GaAs-based power amplifier that saturates at approximately $700 \mathrm{~mW}$ output power with $11 \mathrm{~W}$ input. The amplified power is confined by a single mode 50-75 GHz passband metallic WR-15 waveguide coupled into a custom designed and built S-shaped waveguide split block. The S-shaped waveguide is fabricated in two mirror-image halves and is split along the center of the E-plane where the current flow is zero (Figure 1(c)). A small slot is milled into the center of the S-shaped waveguide
E-plane and intersects the waveguide at the point where the electric field is at a maximum. This slot travels along the E-plane of the guide for its entire length and serves as the sample path for the index-matched Teflon tubing (Zeus Plastics, $0.66 \mathrm{~mm} \mathrm{ID}$, and $1.19 \mathrm{~mm}$ OD, PTFE). The slot is fabricated to ensure no power losses out of the waveguide through the ports. The wavelength of the standing wave in the $S$-shaped waveguide is $\lambda_{0} /\left[1-\left(\mathrm{f}_{\mathrm{c}} / \mathrm{f}\right)^{2}\right]^{1 / 2}$, where $\lambda_{0}(5 \mathrm{~mm})$ is the free space wavelength, $\mathrm{f}(60 \mathrm{GHz})$ is the frequency of the impinging radiation and $f_{c}$ is the cutoff frequency of the waveguide $(39 \mathrm{GHz})$. Power entering the S-shaped waveguide is monitored with a waveguide directional coupler and thermistor power head (PS-28-6, Dorado Company).

During operation, the liquid solution was continuously pumped through the micro-reactor by an ISCO 260D syringe pump. Head pressure (0.17-0.69 $\mathrm{MPa}$ ) was applied to prevent boiling of the sample when it was exposed to RF radiation. The flow restrictor (electroformed nickel tubing, $0.05 \mathrm{~mm}$ I.D., $0.08 \mathrm{~mm}$ O.D., $0.305 \mathrm{~m}$ long, Vici-Valco) was connected to the sample tubing by a micro-volume reducing union (ViciValco) to maintain constant head pressures in the sample line. The sample was loaded with a syringe connected to the sample line by a micro-volume tee-connector (Vici-Valco) and a custom-made Labsmith syringe adapter. Swagelok Valves 1 and 2 controlled the sample loading and the water flow through the micro-reactor's sample handling system.

An output power was measured prior to loading the micro-reactor with sample and was monitored over the course of the experiment. At the start of each experiment, the ISCO syringe pump was programmed to a set head pressure $(0.17-$ $0.69 \mathrm{MPa}$ ) with Valve 2 closed. The micro-reactor sample tubing was primed with $550 \mu \mathrm{L}$ of stock solution by opening Valve 1 . After priming the system, Valve 1 was closed and the flow restrictor was connected to the rest of the assembly. The sample was pressurized by opening Valve 2. The RF power source was then turned on to expose the flowing pressurized sample to $60 \mathrm{GHz}$ radiation at $700 \mathrm{~mW}$ peak power. The hydrolyzed sample was collected at the end of the flow restrictor in a sterile Eppendorf tube. 
(a)

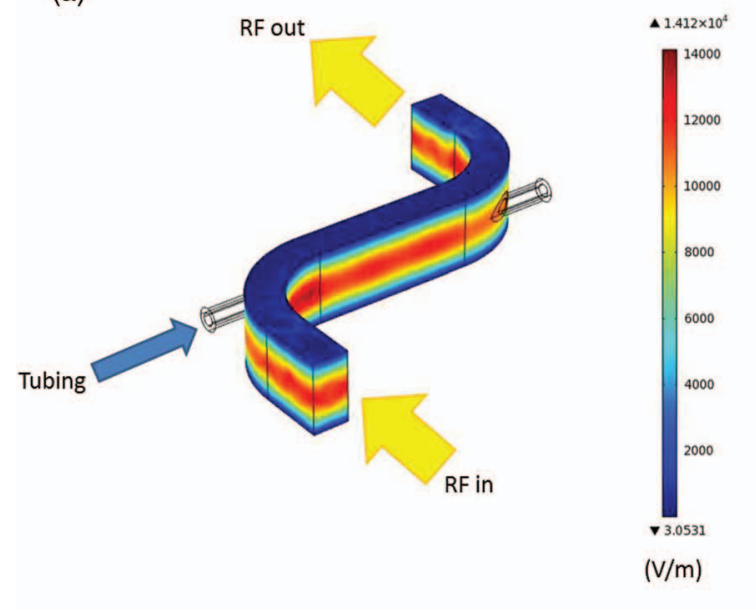

(b)

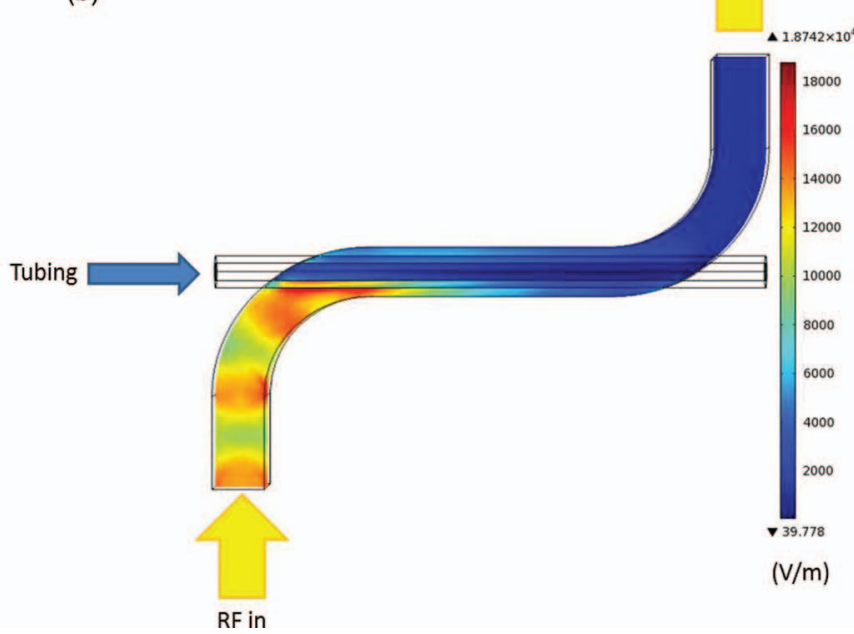

FIG. 2. COMSOL model showing the electric field propagating through the waveguide (a) no water in the sample tubing yielding $3 \%$ power loss and (b) water-filled sample tube.

In each experiment, $350-450 \mu \mathrm{L}$ of hydrolyzed samples were collected to minimize dilution by water from the syringe pump. The flow times and collected volumes were used to estimate the micro-reactor flow rates (5-22 $\mu \mathrm{L} / \mathrm{min})$, which varied as a function of head pressure.

Sucrose and $6 \mathrm{~N} \mathrm{HCl}$ were purchased from SigmaAldrich and used without further purification. $18 \mathrm{M} \Omega \mathrm{DI}$ water was obtained from a Purelab Ultra purification system. Sucrose stock solutions $(1 \mathrm{mg} / \mathrm{mL})$ were prepared in $6 \mathrm{mM} \mathrm{HCl}$ and in DI water. Stock solutions and samples were stored at $8{ }^{\circ} \mathrm{C}$; stock solutions were monitored regularly to ensure no spontaneous hydrolysis was occurring outside of the micro-reactor. Mass spectroscopy (MS) was carried out on a LCQ Advantage Mass Spectrometer in positive ion mode. Samples for nuclear magnetic resonance (NMR) spectroscopy were freeze-dried and dissolved in $\mathrm{D}_{2} \mathrm{O}$. NMR spectra were recorded on a $500 \mathrm{MHz}$ Varian spectrometer.

All simulations were performed with COMSOL Multiphysics 4.2 software with MEMS and RF modules. Pure water was used in place of a sample solution in all of the calculations. An impedance boundary condition was placed on the walls of the waveguide (with dimensions of $1.88 \mathrm{~mm} \times 3.76 \mathrm{~mm})$. The temperature of the walls, the input portion of the Teflon tubing and the liquid entering the micro-reactor S-shaped waveguide were set to $20{ }^{\circ} \mathrm{C}$. The thermal profile of the liquid inside the sample tubing exposed to the $\mathrm{RF}$ radiation was modeled by placing a perfect electric conductor boundary condition on the tubing entrance and exit ports to reduce the RF computational domain. The "normal mesh" setting was used in all of the calculations. An input frequency of $60 \mathrm{GHz}$ in the $\mathrm{TE}_{1,0}$ mode was used for all simulations. Heat transfer and RF propagation were fully coupled. Calculations used a time-dependent model where the temperature distribution was examined after $2 \mathrm{~min}$, which is a sufficient time to reach a steady state. Unless stated otherwise, simulations were run with an input power of $500 \mathrm{~mW}$,
$1 \mu \mathrm{L} / \mathrm{min}$ flow rate, and under 4.05 MPa of pressure. Bubbles were approximated as non-mobile air cylinders $(0.66 \mathrm{~mm}$ diameter and $0.5-4.0 \mathrm{~mm}$ length). The relative permeabilities of water and Teflon were set to $1 \mathrm{~m}^{2}$. Electrical conductivities of Teflon and aluminum were $10^{-12} \mathrm{~S} / \mathrm{m}$ and 2.50637685 $\times 10^{7} \mathrm{~S} / \mathrm{m}$, respectively. Thermodynamic properties of water were calculated using the IAPWS95 formulation. ${ }^{24,25}$ The complex dielectric constant at $60 \mathrm{GHz}$ was calculated using the calculated thermodynamic properties and a Debye relaxation fit. ${ }^{26}$ The static dielectric constant of liquid water at 4.05 $\mathrm{MPa}$ and $250{ }^{\circ} \mathrm{C}$ was calculated using compiled density and viscosity data. ${ }^{27,28}$ A simulated pressure of 4.05 $\mathrm{MPa}$ was chosen to assure that water remained in the liquid phase (Figure 2). Pressure alone had a negligible effect on the simulations and dielectric constants; this was validated by running simulations at $0.91 \mathrm{MPa}$, which showed no appreciable difference $\left(<0.14{ }^{\circ} \mathrm{C}\right.$ change $)$ when there was no phase change. All other parameters for air, water, and the Teflon were taken from the COMSOL materials library.

\section{RESULTS AND DISCUSSION}

The instrument's performance was characterized by measuring the instrument's output and reflected power. For ease of comparison, all values are reported as a percent of the power that reached the waveguide block. With the waveguide block empty, approximately $730 \mathrm{~mW}$ of power entered the waveguide block and $660 \mathrm{~mW}$ of output power was measured, corresponding to approximately $9 \%$ power loss through the S-shaped waveguide. Table I summarizes measurements, adjusted for appropriate losses. When empty, most of the power $(91 \%)$ successfully propagated though the desired path, while a small fraction (4\%) was reflected. Although indexmatched, the Teflon tubing caused higher reflection $(8 \%)$ and slightly less power throughput (89\%). 
TABLE I. Experimental and simulated power measurements for characterization of the micro-reactor.

\begin{tabular}{|c|c|c|c|c|}
\hline Micro-reactor configuration & $\begin{array}{c}\text { Experimental transmitted } \\
\text { power }(\%)^{\mathrm{a}}\end{array}$ & $\begin{array}{c}\text { COMSOL model transmitted } \\
\text { power }(\%)\end{array}$ & $\begin{array}{c}\text { Experimental reflected } \\
\text { power }(\%)^{\mathrm{b}}\end{array}$ & $\begin{array}{c}\text { COMSOL model reflected } \\
\text { power }(\%)\end{array}$ \\
\hline $\begin{array}{l}\text { Waveguide block without Teflon } \\
\text { tubing and sample }\end{array}$ & 91 & 97 & 4 & 2 \\
\hline $\begin{array}{l}\text { Waveguide block with empty } \\
\text { Teflon tubing }\end{array}$ & 89 & 95 & 8 & 3 \\
\hline $\begin{array}{l}\text { Waveguide block with } \\
\text { sample-filled Teflon tube at } \\
0.69 \mathrm{MPa} \text { head pressure }\end{array}$ & 0 & 1 & 3 & 4 \\
\hline
\end{tabular}

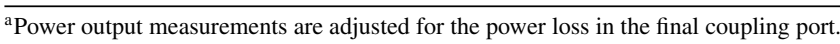

${ }^{\mathrm{b}}$ The reflected power measurements are adjusted for the appropriate power losses as well.

When sample was exposed to RF at atmospheric pressure, the solution boiled yielding power fluctuations inside the waveguide block. The bubbling was alleviated by attaching a flow restrictor to the end of the tubing and using an ISCO syringe pump to control the head pressure; with pressure regulation in place, the output power was zero. At 0.34 and 0.69 $\mathrm{MPa}$ head pressure, little power was reflected, demonstrating that most of the power going into the system was being successfully absorbed; $0.17 \mathrm{MPa}$ head pressure yielded four times as much reflected power. The power measurements clearly suggest that nearly all of the RF radiation is successfully coupled and absorbed by the sample solution in $\mathrm{S}$-shaped waveguide when sample is in a liquid phase. These experimental values agree well with the COMSOL modeling results.

A series of COMSOL simulations were carried out to determine sample temperatures inside the S-shaped waveguide. At $500 \mathrm{~mW}$ input power and $1 \mu \mathrm{L} / \mathrm{min}$ flow rate, the maximum sample temperature was approximately $170{ }^{\circ} \mathrm{C}$. The effect of RF input power on the thermal profile was examined by setting the flow rate constant at $1 \mu \mathrm{L} / \mathrm{min}$ while varying the power from $100 \mathrm{~mW}$ to $900 \mathrm{~mW}$ (Figure 3). Similarly, the effect of the flow rate on the temperature distribution was examined by keeping the input power constant at $500 \mathrm{~mW}$

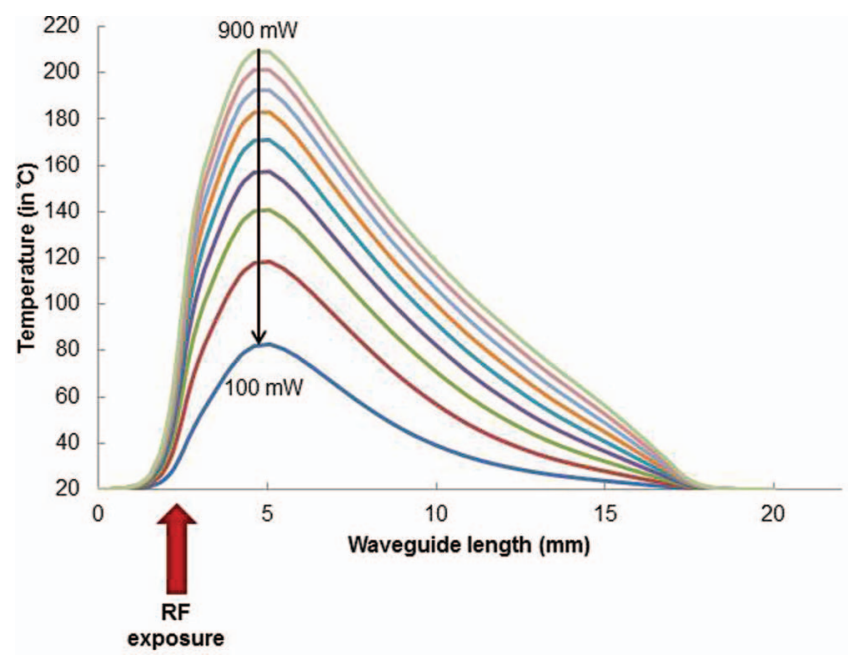

FIG. 3. COMSOL modeling results showing the effect of power input on a sample's thermal profile (in $100 \mathrm{~mW}$ increments). and varying the flow rates (Figure 4). Lower power inputs and faster flow rates yielded lower sample temperatures. At the experimental $730 \mathrm{~mW}$ power input, the models reveal that the aqueous sample reached temperatures above the boiling point of water. In comparison with the experimental flow rates of 5-22 $\mu \mathrm{L} / \mathrm{min}$, the models suggest that the thermal profile will not be greatly affected by this variability in flow rates; however, it should be noted that the residence time, i.e., the amount of time the sample is exposed to the RF radiation, will change significantly.

Boiling and the presence of air bubbles in the sample could compromise chemical reactivity by reflecting the RF input power. Models were used to help grasp the magnitude of the bubble effects on the micro-reactor's performance. When bubbles were positioned near the point of RF radiation incidence, the calculated effects were minimal for all bubbles sizes; a decrease of $11{ }^{\circ} \mathrm{C}$ for a $4 \mathrm{~mm}$ bubble and an increase of $1.5{ }^{\circ} \mathrm{C}$ for a $0.5 \mathrm{~mm}$ bubble were the largest magnitude changes in both directions. Changing the bubble position within the sample tube had a small effect on the temperature-as the bubble was moved away from the point of $\mathrm{RF}$ radiation incidence, the temperature initially increased by about $18{ }^{\circ} \mathrm{C}$, but this effect was quickly attenuated as

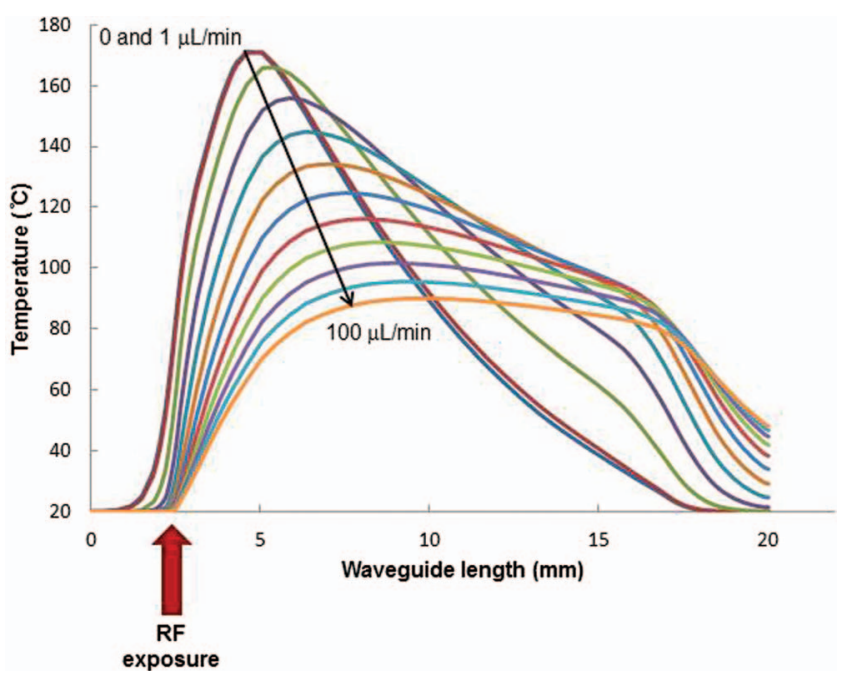

FIG. 4. COMSOL modeling results showing the effect of flow rates on a sample's thermal profile in a micro-reactor S-shaped waveguide (in $10 \mu \mathrm{L} / \mathrm{min}$ increments). 


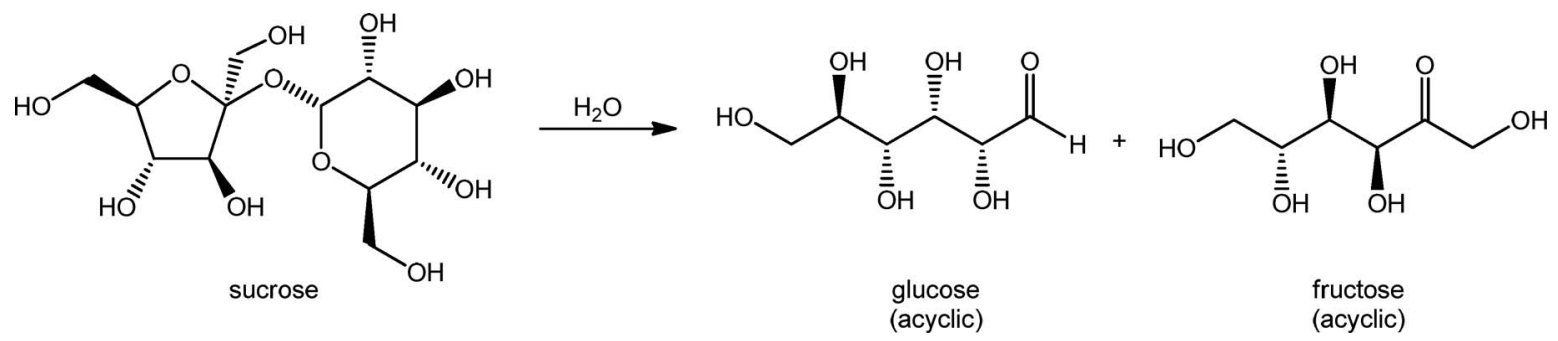

FIG. 5. Hydrolysis of sucrose into monosaccharides glucose and fructose; only the acyclic form of the monosaccharides is shown for simplicity.

the bubble was moved further down the tubing. The modeling data indicated that a small bubble will have little effect on micro-reactor's performance. Presence of several air bubbles within the sample, however, could result in significant temperature fluctuations, which could account in part for the lack of reactivity observed in non-pressurized boiling samples.

Hydrolysis of a disaccharide, sucrose, was used to demonstrate operation of the micro-reactor. Sucrose is hydrolyzed into its monomeric fragments, glucose and fructose, which exist as a mixture of acyclic and cyclic (not shown) forms in a solution (Figure 5).

Sucrose solutions were injected into the micro-reactor and pressurized. Solutions were exposed to RF radiation, collected and analyzed using MS and proton NMR spectroscopy $\left({ }^{1} \mathrm{H}\right.$ NMR). For comparison to RF hydrolysis, thermally induced hydrolysis standards were prepared by heating $400 \mu \mathrm{L}$ aliquots of the stock solutions in Eppendorf tubes to $100{ }^{\circ} \mathrm{C}$ for $24 \mathrm{~h}$. Figure 6 shows the mass spectra of the sucrose stock solution, heat standard, and the micro-reactor samples.

In the stock solution, $365 \mathrm{~m} / \mathrm{z}$ (sucrose $+\mathrm{Na}^{+}$) corresponds to the sucrose parent peak (Figure 6(a)). Heating of the sample at $100{ }^{\circ} \mathrm{C}$ for $24 \mathrm{~h}$ resulted in hydrolysis, yielding a spectrum with two major peaks at 203 and $383 \mathrm{~m} / \mathrm{z}$. These signals correspond to $\mathrm{M}+\mathrm{Na}^{+}$and $2 \mathrm{M}+\mathrm{Na}^{+}$, where $\mathrm{M}$ $=$ monosaccharides glucose and fructose (Figure 6(b)); this assignment was verified independently by recording mass spectra of solutions of glucose and fructose. In the microreactor samples (Figure 6(c)), the sucrose parent $365 \mathrm{~m} / \mathrm{z}$ peak is greatly diminished in comparison to the stock solution spectrum and replaced with the same 203 and $383 \mathrm{~m} / \mathrm{z}$ fragments, confirming that exposure of sucrose to RF in micro-reactor yielded hydrolysis products.

To further determine the extent of hydrolysis, the samples were freeze-dried, dissolved in $\mathrm{D}_{2} \mathrm{O}$ and examined by ${ }^{1} \mathrm{H}$ NMR spectroscopy. The spectra of all micro-reactor samples showed no residual sucrose, indicating that the detected levels of unhydrolyzed sucrose by MS was below the detection limits of the NMR spectrometer (Figure 7).

According to the COMSOL modeling results, the sample temperatures inside the micro-reactor were in the range of $140-180{ }^{\circ} \mathrm{C}$. The micro-reactor's experimental conditions of $730 \mathrm{~mW}$ input RF power and 0.17-0.69 MPa head pressure generated significant hydrolysis in dilute aqueous acid samples. Experiments are underway to determine if other experimental conditions, i.e., different flow rates and input RF
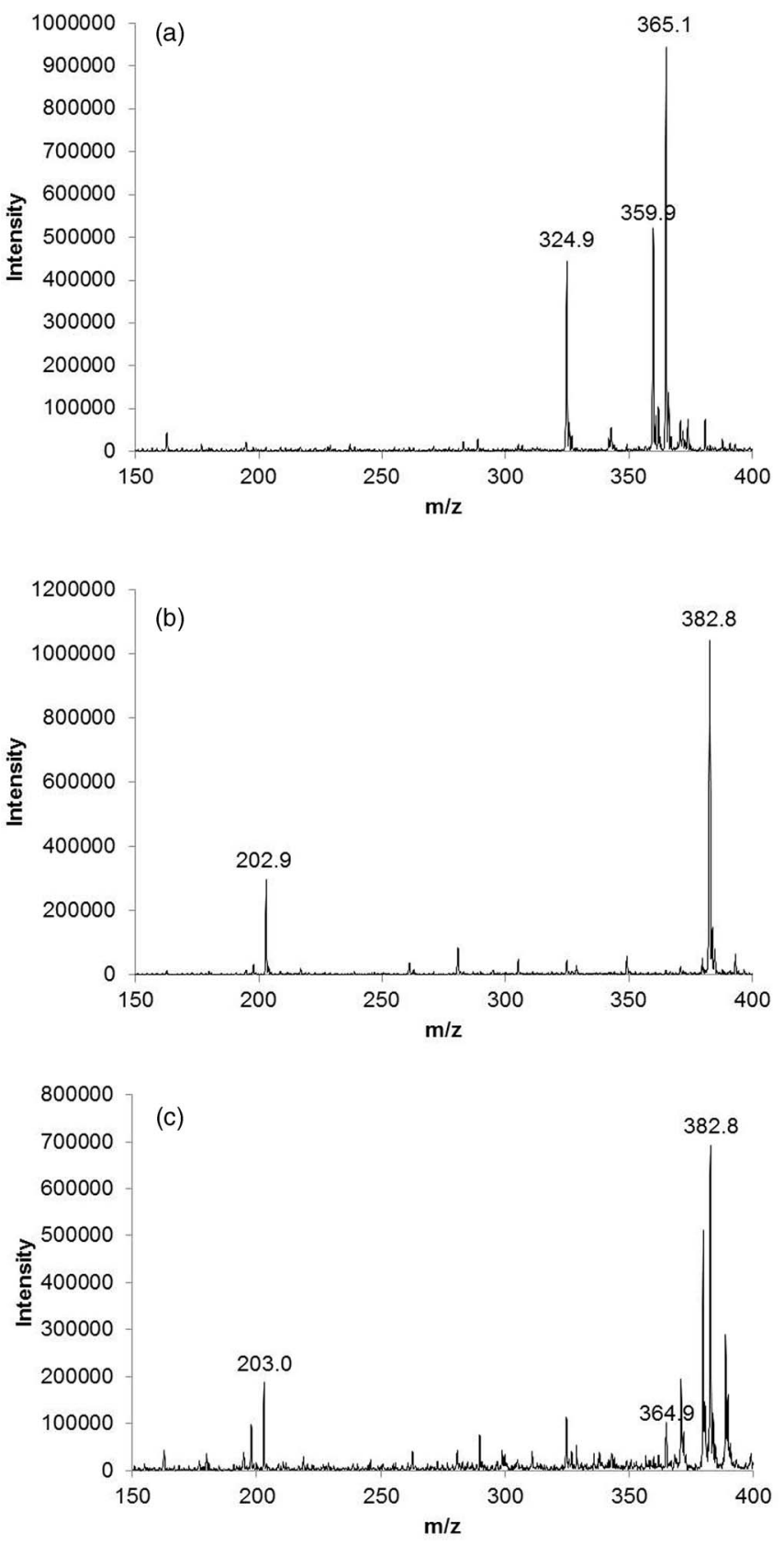

FIG. 6. Mass spectra of (a) stock solution of sucrose in $6 \mathrm{mM} \mathrm{HCl}$, (b) heat standard that was prepared from the stock solution heated to $100{ }^{\circ} \mathrm{C}$ for 24 h, (c) micro-reactor hydrolyzed sample at $0.69 \mathrm{MPa} .365 \mathrm{~m} / z$ peak corresponds to (sucrose $+\mathrm{Na}^{+}$); 203 and $383 \mathrm{~m} / z$ peaks correspond to $\left(\mathrm{M}+\mathrm{Na}^{+}\right.$) and $\left(2 \mathrm{M}+\mathrm{Na}^{+}\right)$, respectively, where $\mathrm{M}$ is monosaccharides glucose and fructose. 


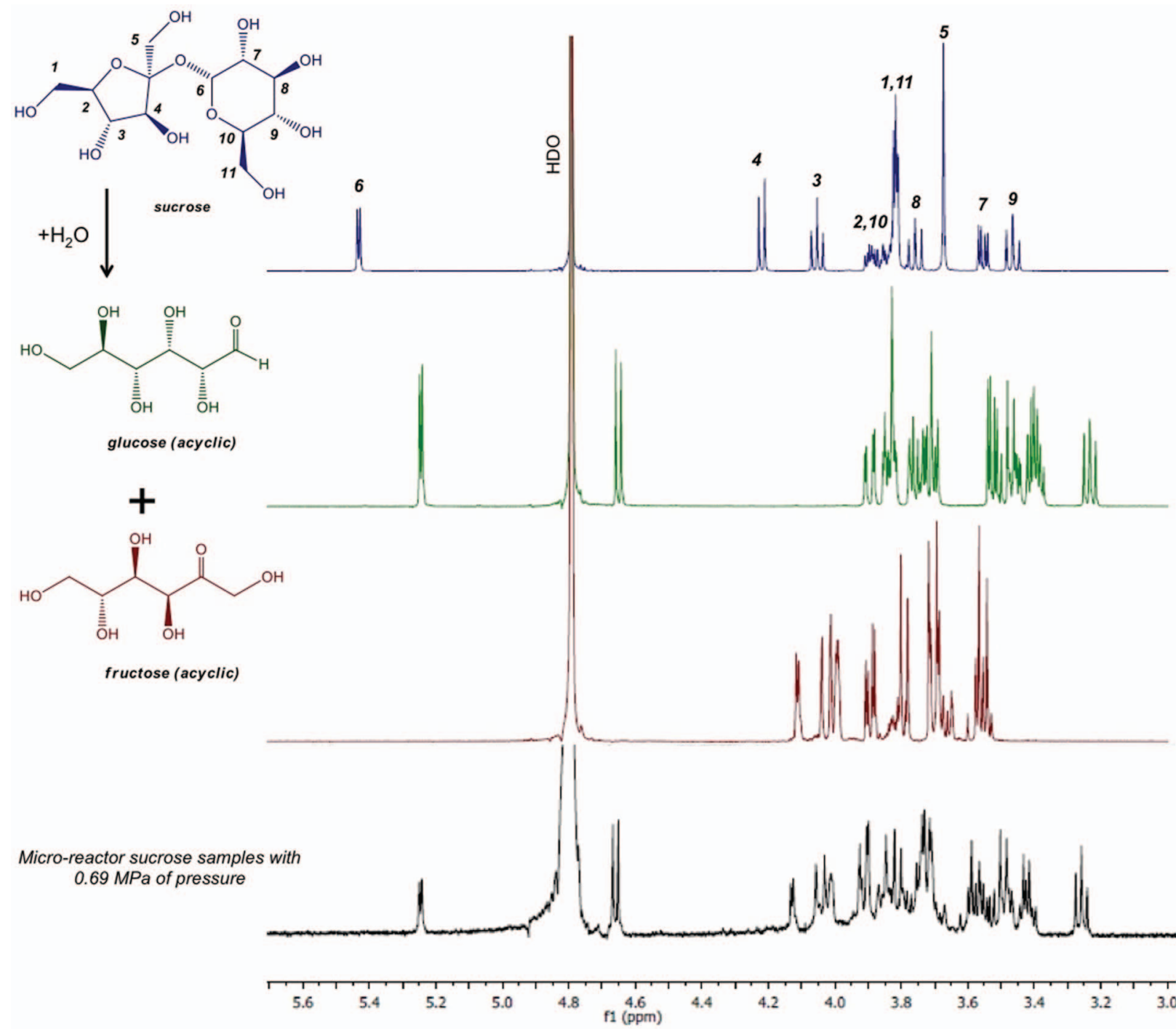

FIG. 7. ${ }^{1} \mathrm{H}$ NMR spectra of sucrose, monosaccharides glucose and fructose, and a spectrum of a sucrose sample in $6 \mathrm{mM}$ HCl subjected to the micro-reactor conditions at $0.69 \mathrm{MPa}$ head pressure.

power, can result in hydrolysis of less-reactive substrates in aqueous solutions.

\section{CONCLUSIONS}

The new micro-reactor instrument described here shows promise as a novel method of sample-processing for in situ space exploration missions. By changing the operating conditions (e.g., RF frequency and power), this technology may be used for extraction of different compounds and hydrolysis of bonds in complex organic and inorganic molecules. The micro-reactor's capabilities for the extraction of a variety of target compounds are under investigation.

\section{ACKNOWLEDGMENTS}

The research described in this paper was carried out at the Jet Propulsion Laboratory (JPL), California Institute of Technology, under contract with the National Aeronautics and
Space Administration. The research was supported through the National Aeronautics and Space Administration (NASA) Planetary Instrument Definition and Development Program; Dr. V. Scott received support through the NASA Postdoctoral Program.

\footnotetext{
${ }^{1}$ Vision and Voyages for Planetary Science in the Decade 2013-2022, Committee on the Planetary Science Decadal Survey, N. R. C. (2011).

${ }^{2}$ R. E. Arvidson, F. Poulet, J. P. Bibring, M. Wolff, A. Gendrin, R. V. Morris, J. J. Freeman, Y. Langevin, N. Mangold, and G. Bellucci, Science 307, 1591-1594 (2005).

${ }^{3}$ A. Gendrin, N. Mangold, J. P. Bibring, Y. Langevin, B. Gondet, F. Poulet, G. Bonello, C. Quantin, J. Mustard, R. Arvidson, and S. LeMouelic, Science 307, 1587-1591 (2005).

${ }^{4}$ Y. Langevin, F. Poulet, J. P. Bibring, B. Schmitt, S. Doute, and B. Gondet, Science 307, 1581-1584 (2005).

${ }^{5}$ J. B. Pollack, J. F. Kasting, S. M. Richardson, and K. Poliakoff, Icarus 71, 203-224 (1987)

${ }^{6}$ S. W. Squyres, J. P. Grotzinger, R. E. Arvidson, J. F. Bell, W. Calvin, P. R. Christensen, B. C. Clark, J. A. Crisp, W. H. Farrand, K. E. Herkenhoff, J. R. Johnson, G. Klingelhofer, A. H. Knoll, S. M. McLennan, H. Y. McSween, R. V. Morris, J. W. Rice, R. Rieder, and L. A. Soderblom, Science 306, 1709-1714 (2004)
} 
${ }^{7}$ A. S. McEwen, L. Ojha, C. M. Dundas, S. S. Mattson, S. Byrne, J. J. Wray, S. C. Cull, S. L. Murchie, N. Thomas, and V. C. Gulick, Science 333, 740 743 (2011)

${ }^{8}$ R. E. Johnson, T. I. Quickenden, P. D. Cooper, A. McKinley, and C. G. Freeman, Astrobiology 3, 823-850 (2003).

${ }^{9}$ G. M. Marion, C. H. Fritsen, H. Eicken, and M. C. Payne, Astrobiology 3, 785-811 (2003).

${ }^{10}$ O. Aharonson, A. G. Hayes, J. I. Lunine, R. D. Lorenz,M. D. Allison, and C. Elachi, Nature Geosci. 2, 851-854 (2009).

${ }^{11}$ C. D. Neish, A. Somogyi, and M. A. Smith, Astrobiology 10, 337-347 (2010).

${ }^{12}$ S. Pilling, D. P. P. Andrade, A. C. Neto, R. Rittner, and A. N. de Brito, J. Phys. Chem. A 113, 11161-11166 (2009).

${ }^{13}$ E. Asphaug, Growth and Evolution of Asteroids, Annual Review of Earth and Planetary Sciences Vol. 37 (Annual Reviews, Palo Alto, 2009), pp. 413-448.

${ }^{14}$ S. A. Benner, K. G. Devine, L. N. Matveeva, and D. H. Powell, Proc. Natl Acad. Sci. U.S.A. 97, 2425-2430 (2000).

${ }^{15}$ D. P. Glavin, M. Schubert, O. Botta, G. Kminek, and J. L. Bada, Earth Planet. Sci. Lett. 185, 1-5 (2001).

${ }^{16}$ M. H. Hecht, S. P. Kounaves, R. C. Quinn, S. J. West, S. M. M. Young, D. W. Ming, D. C. Catling, B. C. Clark, W. V. Boynton, J. Hoffman, L. P. DeFlores, K. Gospodinova, J. Kapit, and P. H. Smith, Science 325, 64-67 (2009).
${ }^{17}$ G. V. Levin and P. A. Straat, EOS Trans. Am. Geophys. Union 58, 829-829 (1977).

${ }^{18}$ V. I. Oyama, B. J. Berdahl, and G. C. Carle, Nature (London) 265, 110-114 (1977).

${ }^{19}$ R. C. Quinn, P. Ehrenfreund, F. J. Grunthaner, C. L. Taylor, and A. P. Zent, J. Geophys. Res. 112, G04S18, doi:10.1029/2006jg000312 (2007).

${ }^{20}$ X. Amashukeli, F. J. Grunthaner, S. B. Patrick, and P. T. Yung, Astrobiology 8, 597-604 (2008).

${ }^{21}$ X. Amashukeli, C. C. Pelletier, J. P. Kirby, and F. J. Grunthaner, J. Geophys. Res. 112, G04S16, doi:10.1029/2006jg000308 (2007).

${ }^{22}$ R. Wolfenden and Y. Yuan, J. Am. Chem. Soc. 130, 7548-7549 (2008).

${ }^{23}$ B. Capon, Chem. Rev. 69, 407-498 (1969).

${ }^{24}$ W. Wagner and A. Pruss, J. Phys. Chem. Ref. Data 31, 387-535 (2002).

${ }^{25}$ P. Junglas, "Implementing the IAPWS-95 standard in MATLAB $囚$," in Proceedings of the 15th International Conference on the Properties of Water and Steam (ICPWS XV, 2008).

${ }^{26}$ K. Okada, Y. Imashuku, and M. Yao, J. Chem. Phys. 107, 9302-9311 (1997).

${ }^{27}$ J. R. Cooper, International Association for the Properties of Water and Steam: Release on the IAPWS Formulation 2008 for the Viscosity of Ordinary Water Substance, IAPWS Release, IAPWS Secretariat, 2008.

${ }^{28}$ M. Uematsu and E. U. Franck, J. Phys. Chem. Ref. Data 9, 1291-1306 (1980) 